Journal of Corporate Real Estate 15, no. 2 (2013): 98-116

\title{
A Study of the Effects of Colocation on Office Workers' Perception
}

\author{
Mahbub Rashid \\ School of Architecture, Design and Planning, \\ University of Kansas, Lawrence, Kansas, USA
}

\begin{abstract}
Purpose - The purpose of study was to understand the effects of colocation on office workers' perception of workplace design and interaction freedom in organizations.

Design/methodology/approach - The study was conducted at six different departments of an office organization that moved from geographically dispersed office buildings to one office building. The premove data were collected three to six months before the move, and the post-move data were collected almost one year after the move through questionnaire surveys. Out of 284 workers, 169 office workers filled out the questionnaire in the pre-move survey, and 175 filled out the questionnaire in the post-move survey.
\end{abstract}

Findings - Based on statistical analyses of the data, the study found that colocation did not help improve office workers' overall perception of interaction freedom in the organization, but it helped eliminate perceptual disparities concerning interaction freedom among its different departments. The study also found that office workers' perception of workplace design support for interaction and workstation location were strong predictors of their perception of interaction freedom in the organization. Overall, the findings of the study indicated that the purpose of colocation might be defeated if organizational behavior and culture were not modified simultaneously to promote workers' perception in support of interaction freedom.

Research limitations - The study considered only one type of colocation that involved bringing people of different organizational units together from geographically dispersed places to one place. Therefore, these findings cannot be generalized for all other types of colocation.

Practical implications - The findings of the study are important for Corporate Real Estate (CRE) strategists and organizational leaders who are actively considering colocation as a strategy to improve interaction and team effectiveness in the organization. 
Originality/value - The study investigates different mechanisms involving the effects of colocation on office workers' perception of workplace design and interaction freedom in organizations; and identifies important distinctions to consider for achieving the benefits of colocation in terms of face-to-face interactions in the workplace.

Keywords - Colocation; Workers' perception; Formal interaction; informal interaction; Workplace design; Workplace location

\section{INTRODUCTION}

Several departments or functional units of an organization are said to be colocated when they share the same space. However, colocation may vary considerably. Concerning who in the units are brought together, in some cases colocation may involve all personnel of different units, whereas in other cases it may involve only a select few from different units. Concerning what is meant by physical proximity of members, in some cases colocation may involve bringing people together from geographically dispersed places to one place. In some other cases, it may involve bringing people together from different floors of a building to one floor. Yet in other cases, it may involve bringing people together from different spaces of one floor to one space. In its more recent use, colocation may also involve people who use the same virtual space but remain separated in physical space (example, Smith \& Reinertsen, 1998).

Dispersed teams, which can be defined as groups of people with a common purpose who carry out interdependent tasks across locations and time using virtual communication technologies (Crampton, 2001: 346), have grown in prevalence in recent years and would seem to offer some advantages over faceto-face teams (Martins et al., 2004; McDonough et al., 2001). Yet, many research studies have concluded that dispersed teams experience more conflict and function less effectively than colocated teams that might meet any one of the many definitions of colocation identified above. More recent examples of these studies include Bourdreau et al., 2012; Canella et al., 2008; Cramton, 2001; Hinds \& Bailey, 2003; Polzer et al., 2006; and van den Bulte \& Moenaert, 1998. This conclusion concerning colocation is particularly important in light of the fact that, collaboration has become the dominant mode of knowledge production and reproduction in many fields due to a need to combine knowledge, expertise or capabilities embodied in different individuals and organizations, (Jones, 2009). For example, team size on scientific papers, an indicator for collaboration in the scientific community, has increased from 1.9 to 3.5 authors per paper since the 1950s (Wuchty et al., 2007). Therefore, we want to know, "why and how does colocation improve face-to-face interaction and teamwork?" 
It is now known that physical environments can influence psychology, behavior, function and performance of individuals, groups and organizations in different ways (for evidence supporting the claim, see Bechtel \& Churchman, 2002; Bell et al., 2005; Gifford, 2002; Steg et al., 2012). These influences are realized via such individual psychological mechanisms as sensory access, attention, memorability or imageability, behavioral affordances, affect, and sociability. The physical environment of workplaces, which include the physical design as well as the ambient environment of workplaces, is no different. Workplace design is particularly important for it also facilitates and/or constrains individual, group and organizational psychology, behaviors, functions and performance to define the organizational and professional environments in the workplace (for evidence supporting the claim, in addition to the above citations also see Appel-Meulenbroek \& Feijts, 2007; de Croon et al, 2005; Haynes, 2007; Lee \& Brand, 2005; Niemi \&Lindholm, 2010; Rashid, et al., 2006, 2009). For example, in a review of literature in fields relevant to Corporate Real Estate (CRE), Appel-Meulenbroek and Feijts (2007) found that as many as 51 aspects of the physical environment of CRE could affect organizational performance. In contrast to the physical enviornment, Haynes (2007) discussed the importance of the social environment of CRE for productivity. More recently, in a review of the methods applied by different parties in the real estate sectors to evaluate office workers' needs and preferences, Niemi and Lindholm (2010) focused not only on the physical, virtual, and social aspects but also the financial aspects of the workplace. That is because, besides its effects on individuals, groups and organizations, workplace design tends to involve relatively fixed and long-lasting features requiring a significant amount of capital investment.

As in any other environments, individual psychological mechanisms often work physically or deontically (that is, according to social and cultural norms, or rules of permissibility and obligation) to influence individual, group and organizational behaviors, functions and performance in the workplace. They work physically when, for example, colocation decreases physical distance and eliminates barriers separating different organizational units to promote interaction among the members of these units at the least cost and effort. This is the primary line of argument presented in the literature in favor of colocation. For example, some authors suggest that the social process of learning and innovation works best when partners are physically close enough to allow frequent interaction and effective exchange of information (for example, Maskell, 2001). Others suggest that close proximity facilitates frequent face-to-face interaction in both formal and informal settings (for example, Salazar \& Holbrook, 2007) leading to the creation of the right environments for collaborative work (for example, Cassiman et al., 2003). That is because repeat interaction enables partners to observe and monitor each other's behavior, providing a means to develop norms of exchange and trust based on the expectation of future interaction. 
One primary reason why workplace design is often recognized as an organizational resource is that it can be used for manipulating physical, visual, and/or network distances among office workers. Whether the intention is to reinforce the already existing patterns of informal communication, or to create new patterns, many new innovative offices capitalize on unplanned, face-to-face interaction traditionally associated with space. These new innovative offices often bring people from dispersed locations into a single workplace that generally consist of smaller individual workspaces to push interaction out of these workspaces into generously provided public or semipublic territories. In these workplaces, spaces are also made highly interconnected with increased visibility, openness, and accessibility in order to boost chance encounters which can lead to meaningful interactions. Additionally, these workplaces also provide a wide variety of features, such as kitchens, stocked refrigerators, central service hubs, recreational facilities, comfortable furniture, and attractive lounge-like spaces in public and/or semipublic territories (Rashid et al., 2006; 2009). A recent publication of the Office of the Government- wide Policy of the General Services Administration of the US Government includes several examples of such innovative offices (OGP, 2002).

The above line of argument in favor of colocation in relation to workers' proximity, however, overlooks the fact that psychological mechanisms also work deontically in relation to the physical environment, as in the case when organizational culture restricts conversations in the corridor or near the water-cooler. This particular phenomenon was well-exposed in a recent field experiment conducted within the Harvard Medical School hospitals and research centers to understand how colocation impacts the likelihood of scientific collaboration (Boudreau et al., 2012). The participants of the study, composed of a group of potential applicants for a research grant, were required to participate in an interactive research symposium. The symposium was structured in a way that all participants were exposed to identical "priming" in a 30-minute general session, but then were randomly assigned to the separate and independent 90-minute breakout sessions. Thus, the authors of the report were able to observe and compare the outcomes of pairs of individuals who participated in the same breakout session in contrast to pairs of individuals who did not. They then estimated the effect of being colocated in the same breakout room on the participants' likelihood of collaboration, or appearing as co-investigators on a grant application. The authors conducting the study interpret being in the same room location at the event as facilitating face-to-face interactions and thus increasing information exchange that may be associated with frictions in the search for collaborators.

The authors reported that while the overall baseline likelihood of any two participants collaborating in a study was small, being in the same room at the event increases the likelihood of collaboration by about $70 \%$. However, they also reported significant interactions between (1) same room and working in the 
same clinical area (2) same room and pairs including a woman, and (3) same room and having published together in the past. Thus, the results indicated that matching between scientists might be subject to considerable frictions characterized by current interests of the parties, personal chemistry and disposition, and timing and scheduling conflicts. This is true even among those scientists in relatively close geographic proximity and in the same organizational system. At the same time, even a brief and focused intervention facilitating face-to-face interactions was able to provide information that impacted the formation of collaborations.

In summary, the literature indicates that for face-to-face interactions to occur workplace design must reduce individual distances to promote environmental access and affordability; but, then, it must also help modify individual, group and organizational psychology, behavior, and culture to promote attention, memorability, affect and/or sociability for the benefits of colocation in terms of face-to-face interactions. The purpose of colocation may be defeated if an organization fails to consider either of these processes. Therefore, one of the specific aims of this study is to find out whether workers from geographically dispersed departments would have less difference in the perception of interaction freedom (that is, where, when, and how to interact in workplace) in colocated departments due to less workplace design disparities. The assumption here is that if workers from different departments perceive interaction freedom differently after colocation, then they may be reluctant to come out of their departmental silos; thus, thwarting any possible gain in interaction due to colocation.

However, support for colocation as a tool for improving interaction is not universal in the literature. One study that provides some contradiction to the interaction benefits of colocation is reported by Kahn and McDonough (1997). For the study the authors surveyed 514 department managers, and found that colocation improved collaboration between research and development (R\&D) and marketing, but not between manufacturing and the other departments because manufacturing worked more independently. They also found no direct relationship between colocation and performance. In other words, according to this study the effects of colocation may not be uniform across various departments of an organization. Therefore, another specific aim of the study is to find out whether the extent of change that occurs in workers' perception due to colocation varies among various departments of an organization. The assumption in this case is that workers from different geographically dispersed departments would have differences in perception concerning any changes in the physical environment due to colocation. While workers from some departments may perceive colocation as an improvement, workers from other departments may perceive it as a decline. As a result, colocation may not always result in an overall improvement in workers' perception, at least along some dimensions, at the organizational level. 
Finally, at least some underlying relationships between workplace design and organization should remain unchanged before and after colocation, therefore providing a way to use workplace design as a tool to influence organizational behavior. For example, if having conference spaces had positive effects on workers' perception of interaction freedom before colocation then having the same after colocation should not have negative effects on workers' perception of interaction freedom. That is because the same workplace design variable should not affect workers' perception in an opposite manner before and after the move unless the people working in the organization have changed in some radical ways, as it might happen if a significant number of people were laid-off at the time of colocation.

\section{METHODS}

\section{Study Design}

The colocation considered in this study involved bringing together six departments of a county government in the USA from geographically dispersed office buildings to one office building (Figure 1). Data were collected at the previous office sites three to six months before the move; and at the new office site one year after the move, thus giving office workers sufficient time to settle into their new workplace after the move. Both pre-move and post-move data were collected from office workers via an anonymous questionnaire. The unit of collection was the office worker, as the aim was to identify changes in office workers' perception after they moved from the old workplaces to the new workplace.

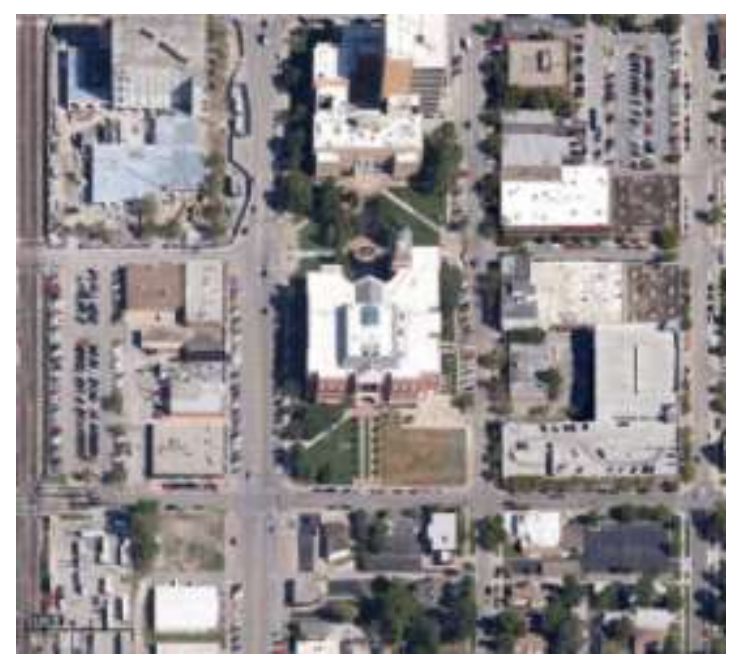

(a)

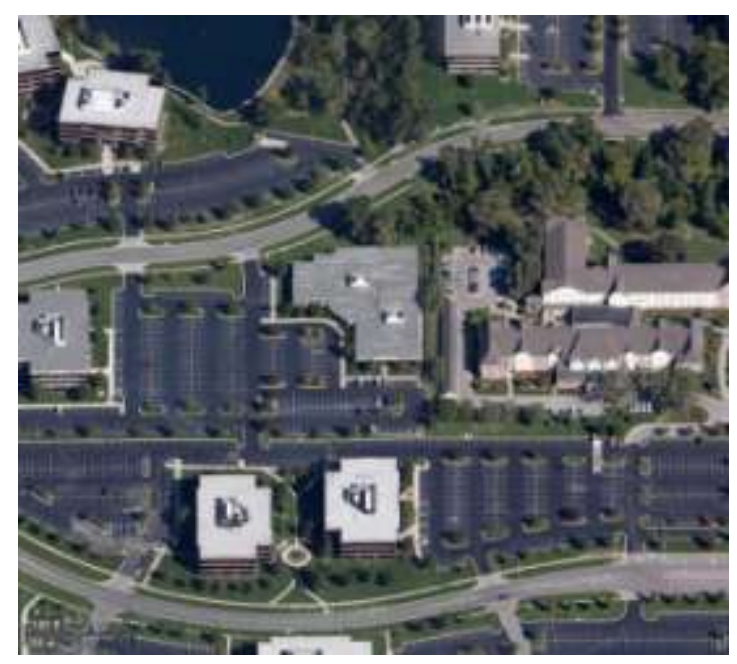

(b) 


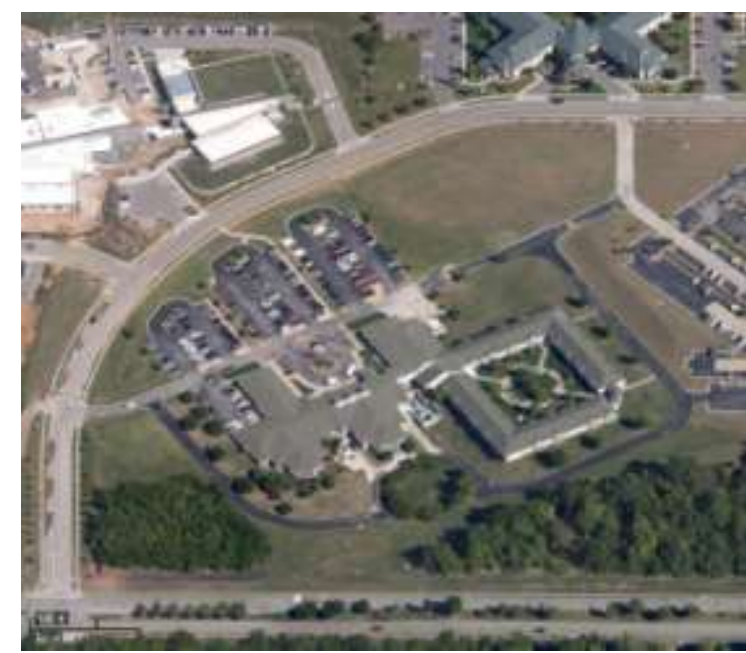

(c)

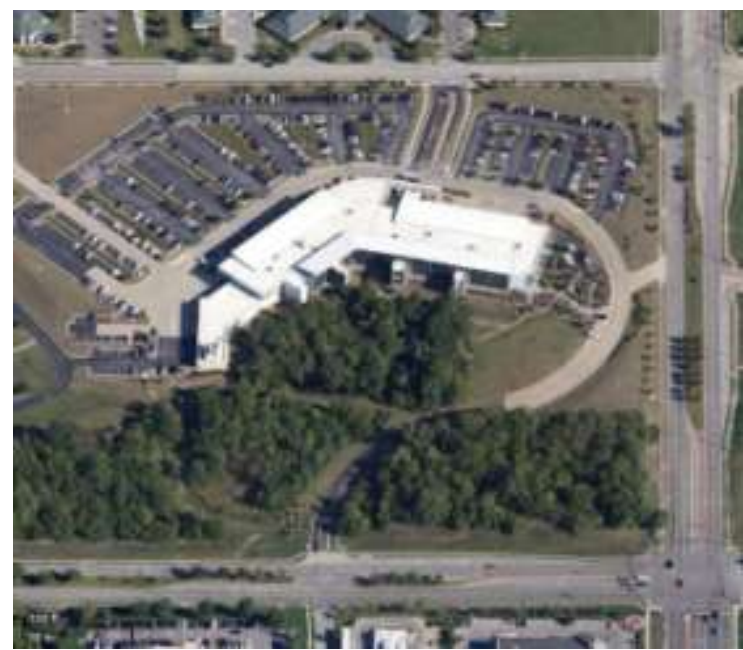

(d)

Figure 1: Aerial views of the old (A, B, \& C) and the new (D) office buildings (source: Google Maps).

\section{Questionnaire}

The questionnaire included several sections of questions concerning individual, workplace design, and organizational factors. Some of these questions were then regrouped to create the multi-item scales described here.

Variables related to personal factors — job character, gender, and age group — were included in the study in order to compare study participants before and after the move.

Scales related to workplace design were as follows: (1) the informal interaction support scale, (2) the formal interaction support scale, and (3) the workplace location scale. The first two of these scales formal and informal interaction support scales —included items related to how workplace design features support formal and informal interactions in the workplace, such as the following: "This office provides shared spaces for teamwork and/or impromptu meetings," "The layout of the departmental workspace supports teamwork," and "The conference and/or training rooms support work tasks." The third scale included items related to location and access to information and office equipment and materials needed for interaction, such as the following: "I have access to the equipment and material I need to get my job done well," and "The office support equipment (fax, photocopy machine, etc.) is convenient to my workspace."

The scales related to organizational environment included the interaction freedom scale only. This scale included items such as the following: "I often stop and talk to others I meet in the corridors or circulation areas of this building," and "I often stop and talk to others I meet in the coffee/snack bar of this building." 
In summary, the workplaces design scales included items describing workers' perception of access to and availability of people and resources needed for interaction and team work; and the organizational environment scale included items describing workers' perception of where, when and how office workers could interact. Table 1 lists all the items included in each of the above scales.

\section{Participating Units and Their Workplaces Before and After the Move}

Each of the participating six departments of the county government performs functions different from the others. One of these departments is assigned the task of appraising real estate and personal property at fair market value for tax purposes. The second is assigned the task of environmental administration. The third is assigned the task of providing essential human services that support the independence, dignity and selfsufficiency of the county residents. The fourth is assigned the task of providing adult and youth

\begin{tabular}{|c|c|c|c|}
\hline \multicolumn{3}{|c|}{ Environmental design factors } & \multirow{2}{*}{\begin{tabular}{|l|}
\multicolumn{1}{|c}{$\begin{array}{c}\text { Organizational environment } \\
\text { factor }\end{array}$} \\
$\begin{array}{l}\text { Interaction freedom scale } \\
(\text { Cronbach's Alpha }=0.7)\end{array}$
\end{tabular}} \\
\hline $\begin{array}{l}\text { Workstation location scale } \\
(\text { Cronbach's Alpha }=0.72)\end{array}$ & $\begin{array}{l}\text { Informal interaction } \\
\text { support scale (Cronbach's } \\
\text { Alpha }=0.74)\end{array}$ & $\begin{array}{l}\text { Formal interaction } \\
\text { support scale (Cronbach's } \\
\text { Alpha }=0.75)\end{array}$ & \\
\hline $\begin{array}{l}\text { 1. I have access to the } \\
\text { equipment and material I } \\
\text { need to get my job done } \\
\text { well. } \\
\text { 2. When I need information } \\
\text { from co-workers in order } \\
\text { to do my work, I have to } \\
\text { go out of my way to get } \\
\text { it. } \text { ß } \\
\text { 3. The office support } \\
\text { equipment (fax, photocopy } \\
\text { machine, etc.) is } \\
\text { convenient to my } \\
\text { workspace. } \\
\text { 4. Overall, I am pleased with } \\
\text { the location of my personal } \\
\text { workspace within this } \\
\text { department. }\end{array}$ & $\begin{array}{l}\text { 1. This building provides } \\
\text { many opportunities for } \\
\text { informal conversations } \\
\text { with others. } \\
\text { 2. The people I need to work } \\
\text { with most often are } \\
\text { located close to my } \\
\text { workspace. } \\
\text { 3. This office provides } \\
\text { shared spaces for } \\
\text { teamwork and/or } \\
\text { impromptu meetings. } \\
\text { 4. I often have difficulty } \\
\text { finding the people I need } \\
\text { to get my work done. }{ }^{\circledR} \\
\text { The layout of the } \\
\text { departmental workspace } \\
\text { supports teamwork. } \\
\text { The layout of the } \\
\text { departmental workspace } \\
\text { supports impromptu } \\
\text { meetings. } \\
\text { This office lacks informal } \\
\text { meeting spaces. }{ }^{\circledR}\end{array}$ & $\begin{array}{l}\text { 1. The conference and/or } \\
\text { training rooms support } \\
\text { work tasks. } \\
\text { 2. When I need to schedule } \\
\text { a conference space, } \\
\text { there is one available. } \\
\text { 3. The sizes of conference } \\
\text { spaces fit our needs. }\end{array}$ & $\begin{array}{l}\text { 1. I often stop and talk to } \\
\text { others I meet in the } \\
\text { corridors or circulation areas } \\
\text { of this building. } \\
\text { 2. I often stop and talk to } \\
\text { others I meet in the } \\
\text { lounge/break-room of this } \\
\text { building. } \\
\text { 3. I often stop and talk to } \\
\text { others I meet in the } \\
\text { coffee/snack bar of this } \\
\text { building. } \\
\text { 4. So long as I get my job } \\
\text { done, I can choose where in } \\
\text { the building I do it. }\end{array}$ \\
\hline
\end{tabular}

(B) refers to items which were scored in reverse.

Table 1: Items included in the multi-item scales used in the study

educational programs. The fifth is assigned the task of providing emergency medical services. Finally, the sixth department is assigned the task of ensuring that the streams, rivers and lakes of the county are free 
from disease-causing bacteria and viruses that are harmful to the public health. Therefore, it was assumed that even after the move these departments would remain functionally independent from each other highlighting differential effects of colocation on workers' perception. Since there was very little or no movement of human resources in these departments during the study period, it was also assumed that any changes in departmental differences in workers' perception would be caused by changes in interdepartmental proximity and physical design changes resulting from colocation rather than by any intradepartmental cultural changes .
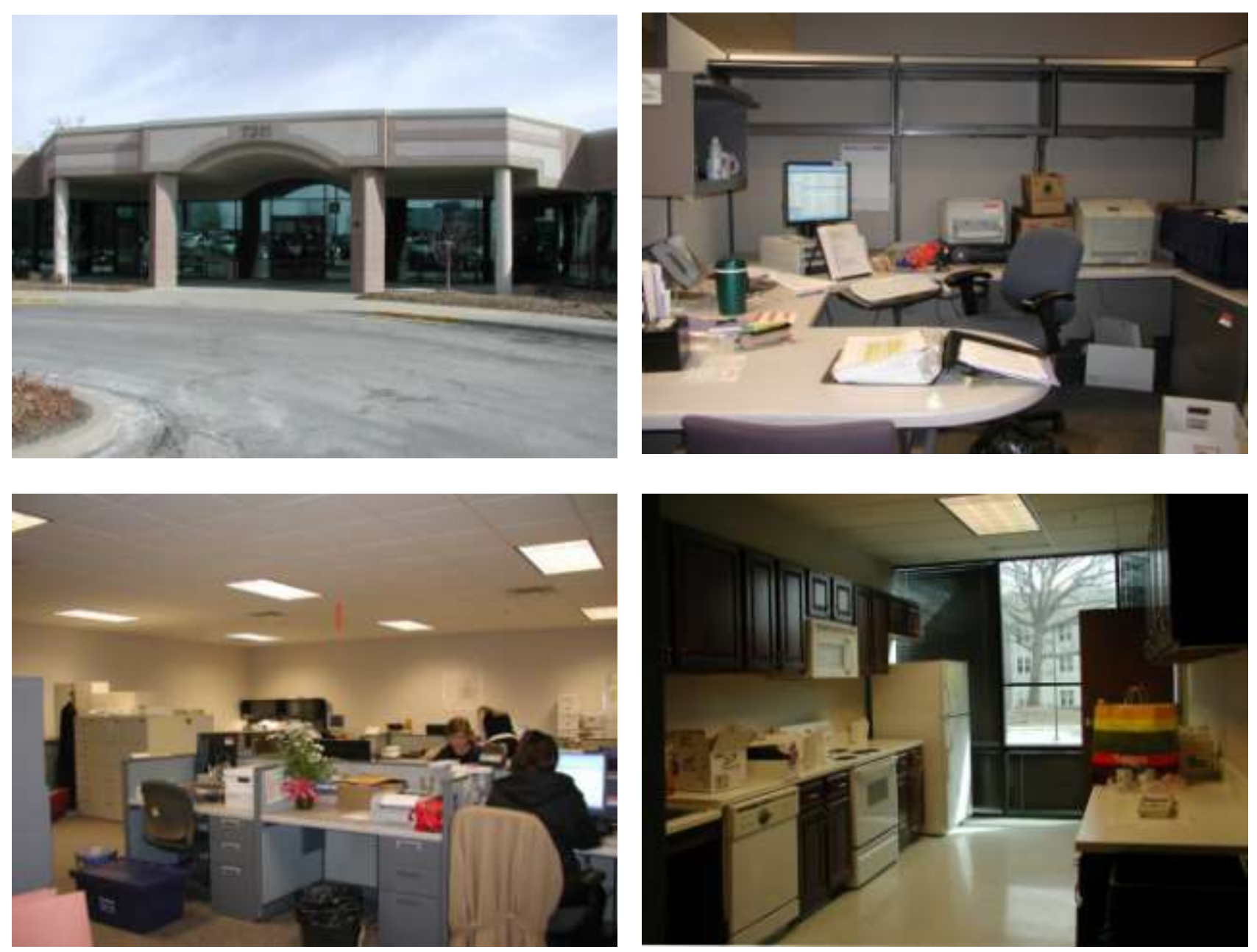

Figure 2: Photographs of an old office building and a few selected spaces in the building

As noted above, before the move these departments were located in separate buildings at multiple county locations (Figure 1). Figure 2 includes a set of photographs of one of the old office buildings and a few selected spaces in the building. Each of the old offices, like any common "spec" office spaces, had open systems workstations inside and private offices with systems furniture around the perimeter. As a result, 
many workers did not have access to natural light and/or outside view. The corridors within each office did not have sufficient natural light either. Each office included various amenities, such as one or more conference spaces, common work areas with photocopiers, printers and fax-machine, a kitchenette, an office lounge, water cooler/s, and storage spaces. Yet, in many of these old offices the common areas did not feel right for face-to-face interaction. They were too small, located to too far away from a large number of workstations, and/or were enclosed spaces that negatively affected their visual and physical access (Figures 3 \& 4). Therefore, it was assumed that some differential effects of colocation on workers' perception of workstation location in relation to common areas would exist at the departmental level of the organization. In some cases, these common areas would support interactions better than they would in the other cases.

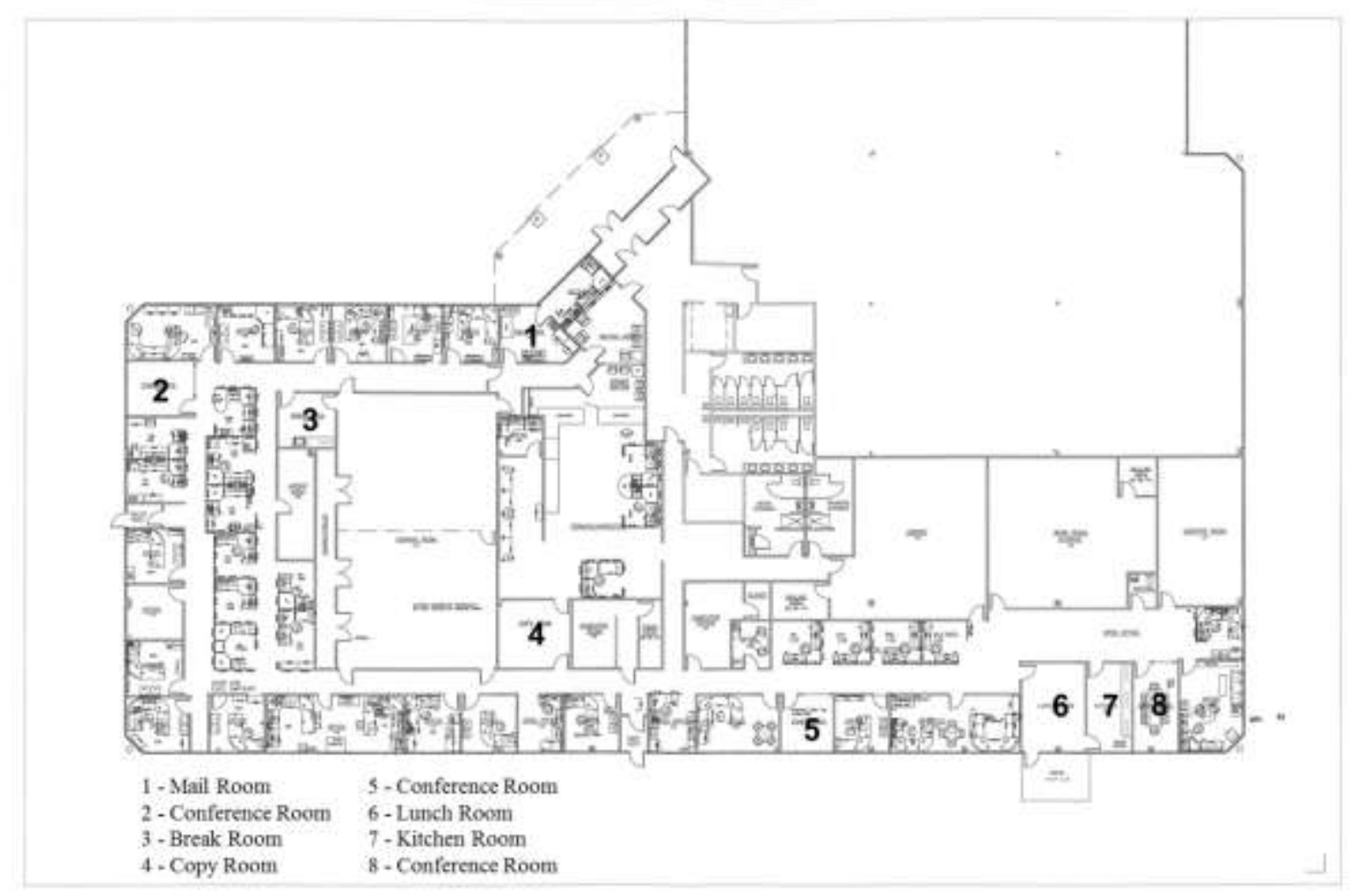

Figure 3: Floor plan of an old workplace showing common areas and amenities.

It should also be noted here that while workplace design at the old offices were somewhat similar, the locations of these offices were not. Some of these offices were located in suburban areas (Figure 1B\&C), and the others were located in more congested downtown areas (Figure 1-A). As a result, workers in the suburban locations could simply park their cars in the parking lots outside the buildings and walk to their work without crossing any streets, while workers in the downtown location needed to park their cars 
in the parking deck across a busy street. Also, in some of these locations offices were located on the first floor, while in the other locations workers needed to use stairs or elevators to get to their offices.

Therefore, it was also assumed that some differential effects of colocation on workers' perception of workplace design in general would exist at the departmental level since they were coming from suburban and downtown locations.
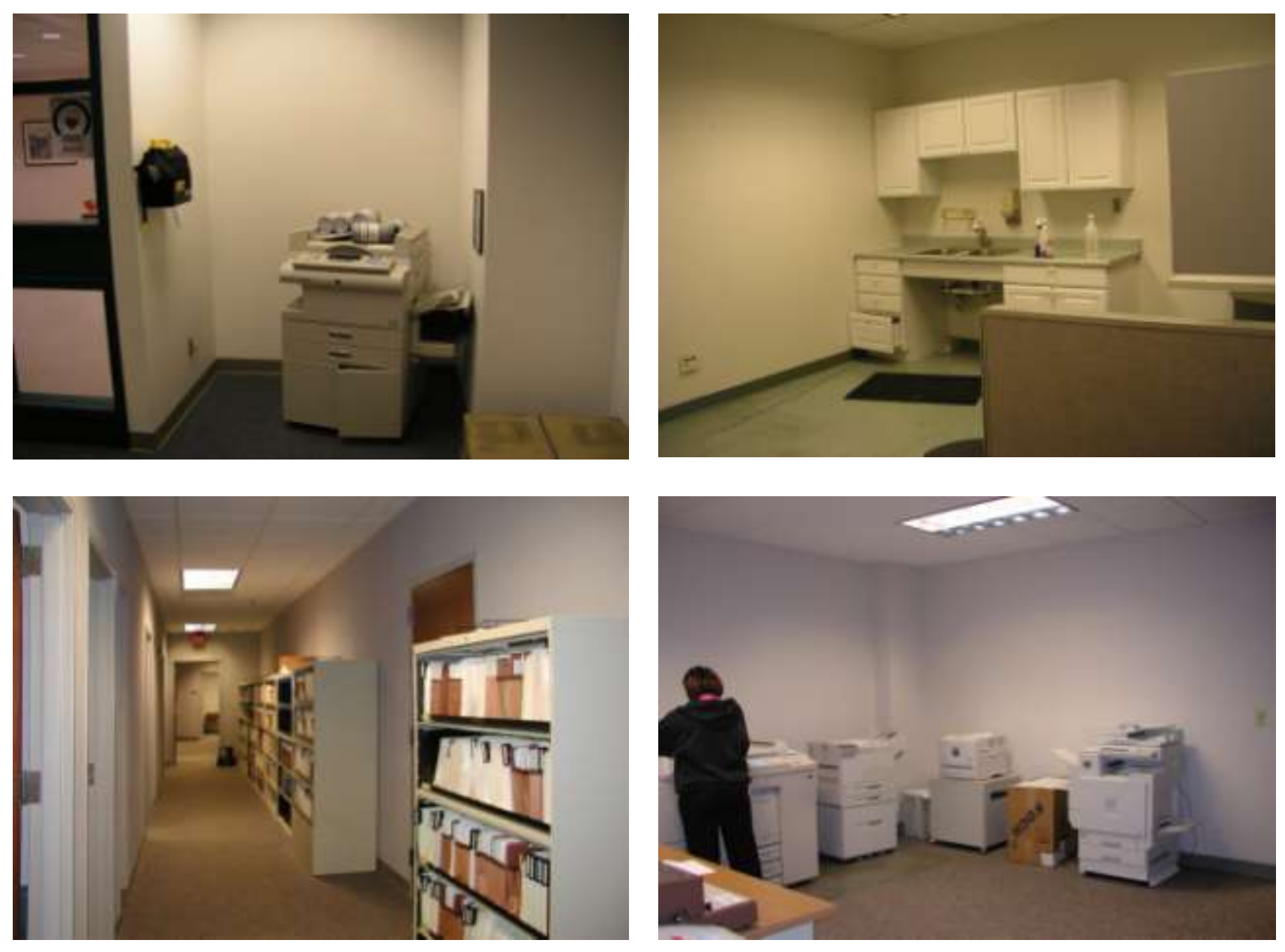

Figure 4: Photographs showing some of the common areas and amenities in old workplaces.

All the participating departments then moved to a newly built LEED-certified office building. Figure 5 includes a set of photographs of the new office building and a few selected spaces in the building. In the new building, each department still has a well-defined area. However, in contrast to the old buildings, in the new building private offices are placed inside and workstations are placed around the perimeter. As a result, more workers now have access to natural light and outside view. In the new building, not only are the departments colocated, they also share several amenities including parking areas, a huge well-lit 
atrium, well-lit corridors with invitingly warm woodwork, conference spaces with outdoor views, and improved service areas. In addition, most common amenities in the new building are located along a south-facing concourse that is easily accessible from all the departments (Figure 6). Therefore, it was assumed that workers at the new workplace would have more opportunities to interact with others across departments causing any differences in office workers' perception observed at the old workplaces to diminish.
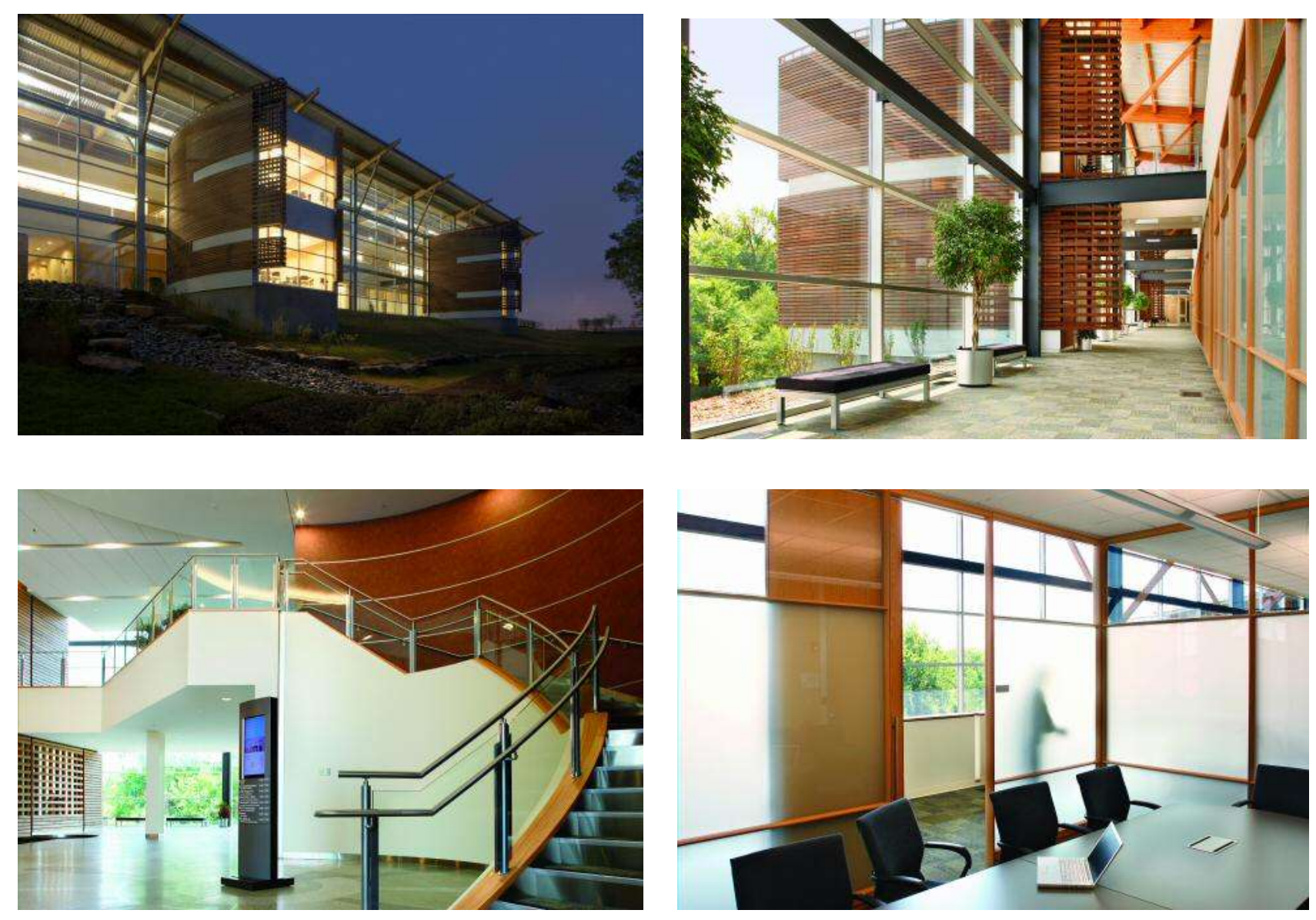

Figure 5: Photographs of the new office building and a few selected spaces in the building

\section{Data Collection}

Institutional Review Board (IRB) approval was obtained from the Human Subjects Committee of the involved institutions. Participation in the study was voluntary. The IRB-required information and cover sheets were attached to the questionnaire to ensure that a participating office worker fully understood the intent of the study and the consequences of his/her participation. Strategies to inform office workers about the study included presentations at the managers and administrators' meetings at each of the six 
departments. The managers and administrators then had informed office workers in their offices of the survey via email or memo. Office workers were given one week to complete the questionnaire after it was handed to them. The one-week response time was given to ensure a high response rate. The respondents returned the questionnaire to a box kept at a predetermined place in their offices. The same questionnaire was used for collecting data in the pre-move and post-move phases for comparing changes in workers' perception before and after the move.

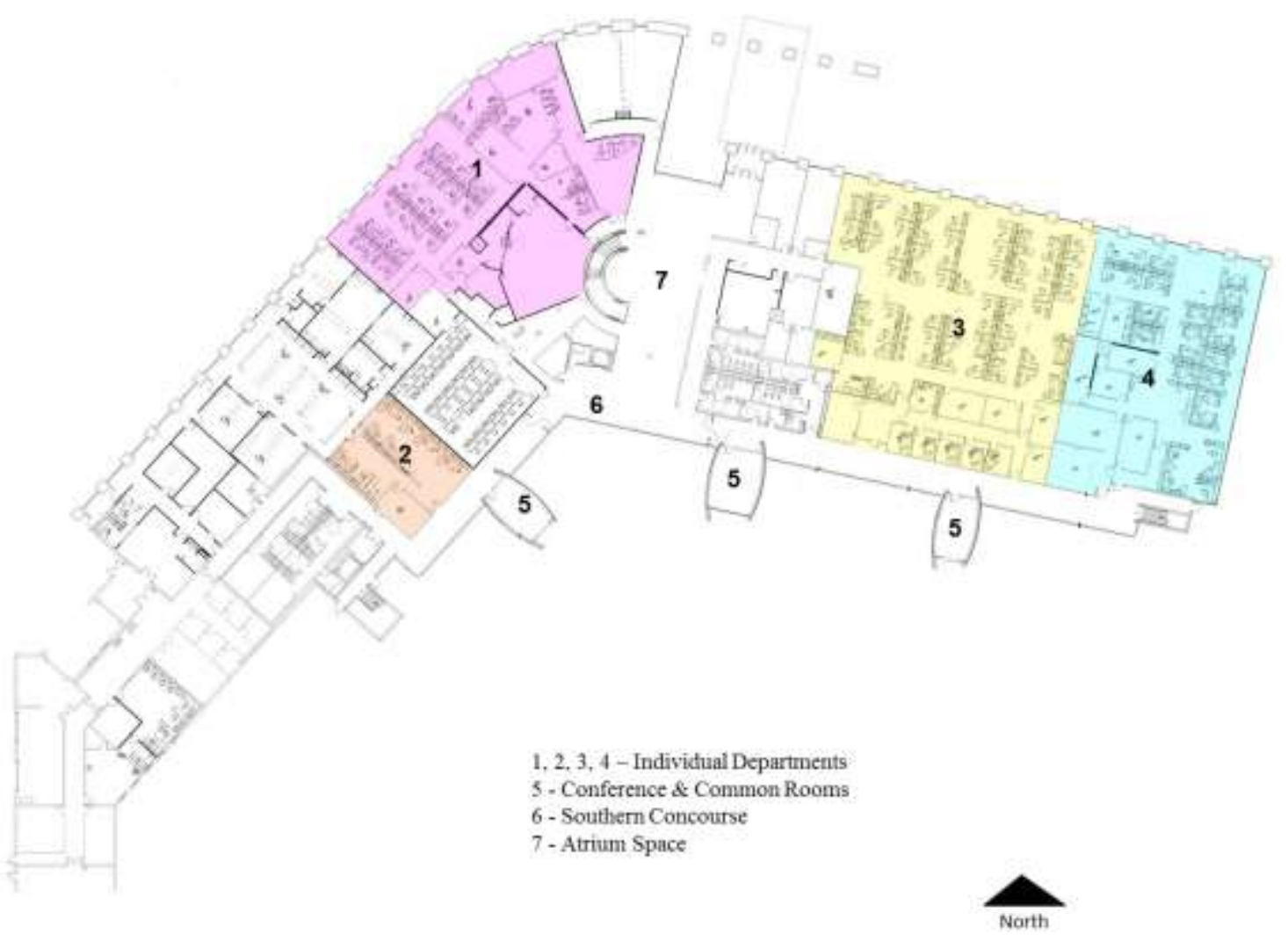

Figure 6: Floor plan of the first floor of the new workplace showing four of the six departments and common areas.

\section{ANALYSIS AND RESULTS}

Questionnaire data were manually entered into an SPSS (SPSS Inc., Chicago, IL) database. Standard data checking and verification were performed (for example, range, distribution, and pattern of missing values). Altogether, the six departments had 284 workers at the time of the surveys. The sizes of these departments varied between 93 and 19 workers. At the old workplaces, 169 returned an appropriately filled out questionnaire (response rate: 59.5\%). Departmental response rates at the old workplaces varied between $77.4 \%$ and $29.3 \%$. At the new workplace, 175 office workers returned an appropriately filled out 
questionnaire (response rate: 61.6\%). Departmental response rates at the new workplace varied between $80.6 \%$ and $42.1 \%$ (Table 2). For one of the sites, the response rates in one case in both the before- and after-move surveys were somewhat low, yet the numbers were large enough to get significant statistical results using Levene and ANOVA statistics.

Factor analyses returned one primary component for each multi-item scale. Therefore, there was no need to regroup the items to define sub-scales or to eliminate any item from any scale. Reliability analyses for all the scales were completed using Cronbach's alpha. Cronbach's alpha is widely believed to indicate indirectly the degree to which a set of items measures a latent construct. Nunnally (1978) suggests 0.7 or above as acceptable Cronbach's alpha for social and psychological studies. Accordingly, each scale used in the study had acceptable Cronbach's alpha values (Table 1).

To find out whether workers from geographically dispersed departments would have less difference in the perception of interaction freedom (that is, where, when, and how to interact in workplace) in colocated departments due to less workplace design disparities, first ANOVA was performed for gender, age, and job level of the pre-move and post-move survey participants from each department to establish that these groups were statistically similar. Once this was established, ANOVA was performed again for the interaction freedom scale to find out how different these groups were concerning interaction freedom before and after the move (Table 3). Since the Levene statistics for the significance values for homogeneity of variances were $>.05$ for both cases, it was assumed that the Levene statistics supported the null hypothesis that the group variances were equal for the pre- and post-move survey participants and ANOVA could be used to test the differences between the pre- and post-move groups. The ANOVA statistics showed that for the interaction freedom scale the significance value was 0.05 before the move and >.05 after the move. Therefore, based on both the Levene and ANOVA statistics it can be concluded that for the interaction freedom scale there were significant differences among the pre-move survey participants at the departmental level, but this difference had disappeared after the move.

Means of different scales for each department before and after the move were compared to find out whether the extent of change that occurs in workers' perception due to colocation varies among various departments of an organization (Table 4, Figures 7 \& 8). For department A, all of the four scales showed some improvement. For department B, all three workplace design assessment scales showed some improvement but the interaction freedom scale showed a decline. For department $\mathrm{C}$, two of the three workplace design assessment scales showed a decline, while the third showed some improvement. The interaction freedom scale also showed a decline in this department. While individuals had a positive view of this factor $(+3.5)$ before the move, they had a neutral opinion of the same factor after the move (0). For 
department D, two of the three workplace design assessment scales showed some improvement, while the third showed a decline. The interaction freedom scale also showed a decline in this department. For department E, two of the three workplace design assessment scales showed a decline, while the third showed some improvement. The interaction freedom scale also showed a decline in this department. For department F, all of the four scales showed a decline. In summary, colocation did not have consistent effects on these departments with regard to informal interaction support, formal interaction support, workplace location, and interaction freedom. This inconsistency may be a result of the functional differences that existed among the organizational units (see above in the description of the participating units), an issue that will also be discussed later in the paper. Overall, at the organizational level an increase for the three workplace design assessment scales and a decrease for the interaction freedom scale were observed.

\begin{tabular}{|c|c|c|c|c|c|c|c|}
\hline & All Departments & A & B & $\mathrm{C}$ & $\mathrm{D}$ & $\mathrm{E}$ & $\mathrm{F}$ \\
\hline Total number of employees & 284 & 93 & 31 & 19 & 58 & 26 & 57 \\
\hline $\begin{array}{l}\text { Number of returned pre-move survey } \\
\text { (\% of the total number of employees) }\end{array}$ & $\begin{array}{l}169 \\
(59.5)\end{array}$ & $\begin{array}{l}62 \\
(66.7)\end{array}$ & $\begin{array}{l}24 \\
(77.4)\end{array}$ & $\begin{array}{l}9 \\
(47.7)\end{array}$ & $\begin{array}{l}17 \\
(29.3)\end{array}$ & $\begin{array}{l}19 \\
(73)\end{array}$ & $\begin{array}{l}38 \\
(66.7)\end{array}$ \\
\hline $\begin{array}{l}\text { Number of returned after-move survey } \\
\text { (\% of the total number of employees) }\end{array}$ & $\begin{array}{l}175 \\
(61.6)\end{array}$ & $\begin{array}{l}48 \\
(51.6)\end{array}$ & $\begin{array}{l}25 \\
(80.6)\end{array}$ & $\begin{array}{l}8 \\
(42.1)\end{array}$ & $\begin{array}{l}30 \\
(51.7)\end{array}$ & $\begin{array}{l}16 \\
(61.5)\end{array}$ & $\begin{array}{l}42 \\
(73.7)\end{array}$ \\
\hline
\end{tabular}

Table 2: The numbers of participants from each department in the pre-move and the post-move surveys

\begin{tabular}{|l|l|l|l|l|l|l|l|l|l|l|l|}
\hline & \multicolumn{9}{|l|}{$\begin{array}{l}\text { Test of Homogeneity of } \\
\text { Variances }\end{array}$} & \multicolumn{1}{l|}{ ANOVA } \\
\hline & & $\begin{array}{l}\text { Levene } \\
\text { Statistic }\end{array}$ & df1 & df2 & Sig. & $\begin{array}{l}\text { Sum of } \\
\text { Squares }\end{array}$ & df & $\begin{array}{l}\text { Mean } \\
\text { Square }\end{array}$ & F & Sig. \\
\hline Interaction Freedom Scale & Pre-move & 1.76 & 5 & 163 & .12 & 132.01 & 5 & 26.40 & 2.31 & .05 \\
\hline & Post-move & 1.98 & 5 & 163 & .08 & 57.58 & 5 & 11.52 & .99 & .42 \\
\hline
\end{tabular}

Table 3: Differences between the pre-move and post-move survey participants' perception of interaction freedom at the organizational level

\begin{tabular}{|l|l|l|l|l|l|l|l|l|l|l|l|l|l|l|l|l|}
\hline & A & \multicolumn{3}{|l|}{ B } & \multicolumn{2}{l|}{ C } & \multicolumn{2}{l|}{ D } & \multicolumn{2}{l|}{ F } & \multicolumn{2}{l|}{ Total } \\
\hline & Pre & Post & Pre & Post & Pre & Post & Pre & Post & Pre & Post & Pre & Post & Pre & Post \\
\hline Informal Interaction Support Scale & 2.6 & 3.89 & 5.18 & 7.25 & 9.72 & 4.63 & 5.81 & 5.76 & 4.35 & 3.63 & 4.16 & 2.17 & 4.22 & 4.28 \\
\hline Formal Interaction Support Scale & 0.07 & 1.84 & 0.61 & 2.69 & 1.17 & 2 & 1.47 & 2.11 & 1.81 & 0.06 & 2.78 & 0.12 & 1.15 & 1.43 \\
\hline
\end{tabular}




\begin{tabular}{|c|c|c|c|c|c|c|c|c|c|c|c|c|c|c|}
\hline Workspace Location Scale & 1.92 & 2.72 & 2.6 & 4.25 & 4.11 & 2.88 & 3.82 & 4.62 & 2.84 & 3.19 & 3.53 & 2.9 & 2.8 & 3.37 \\
\hline Interaction Freedom Scale & 0.69 & 0.72 & 2.49 & 1.23 & 3.5 & 0 & 0.82 & 0.63 & 1.35 & 0.56 & 0.35 & -0.48 & 1.11 & 0.43 \\
\hline
\end{tabular}

Table 4: Office workers' perception before and after the move given by departments

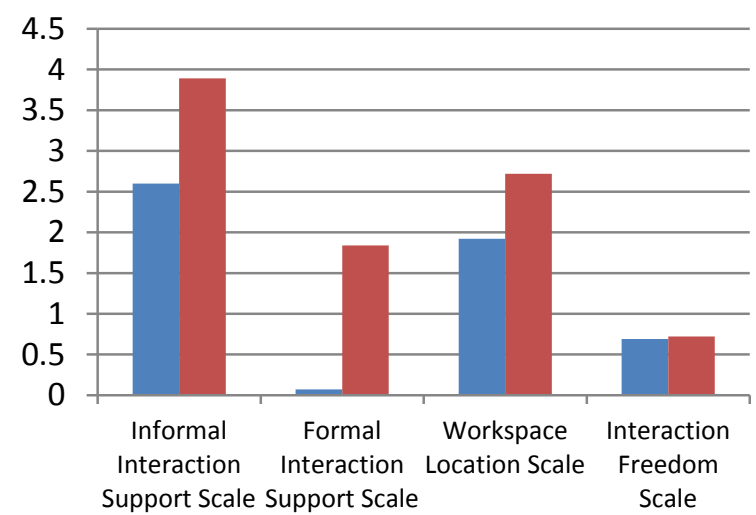

(a)

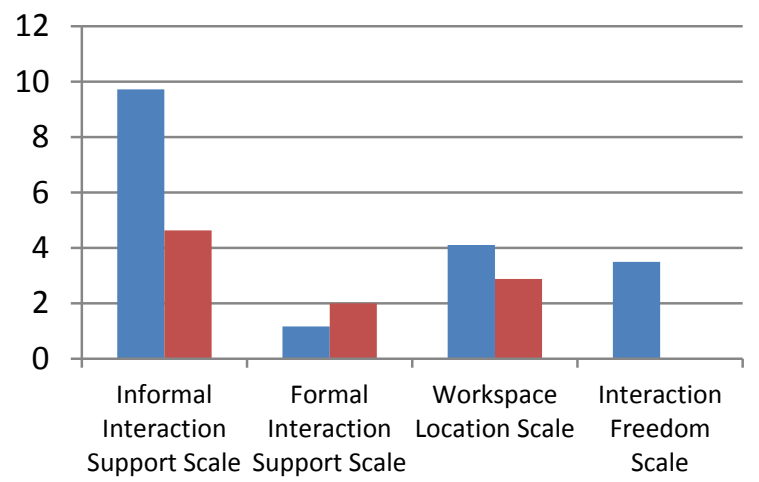

(c)

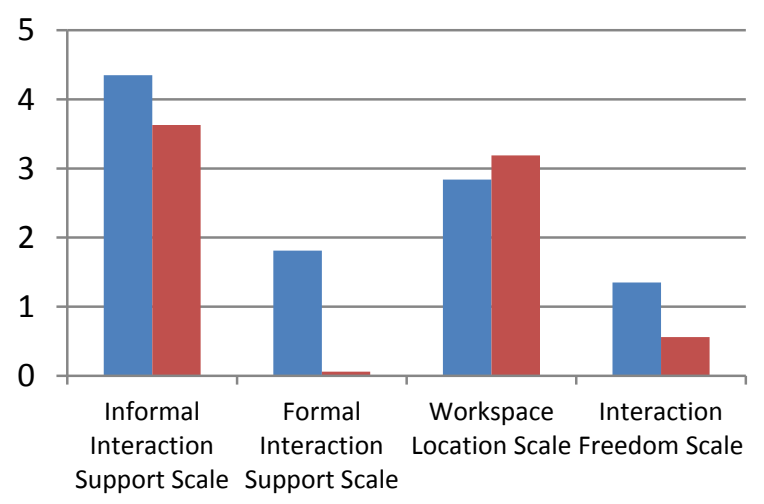

(e)

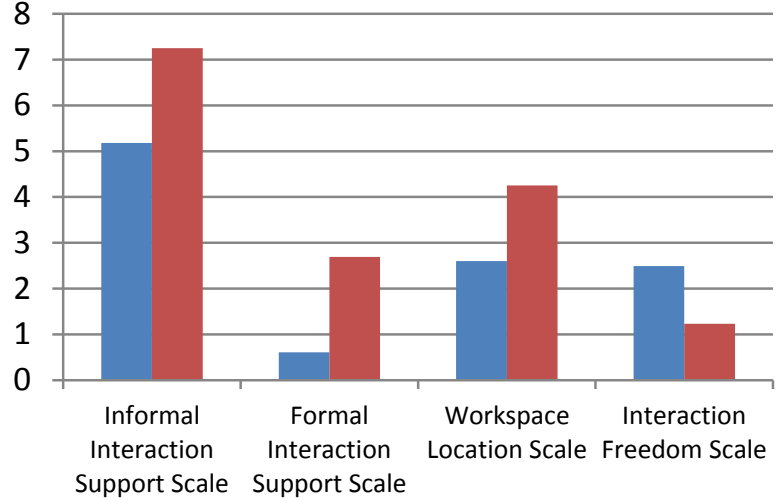

(b)

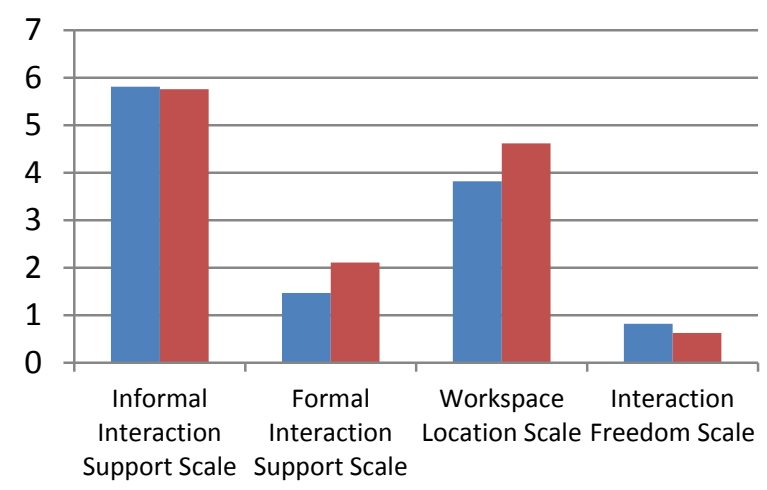

(d)

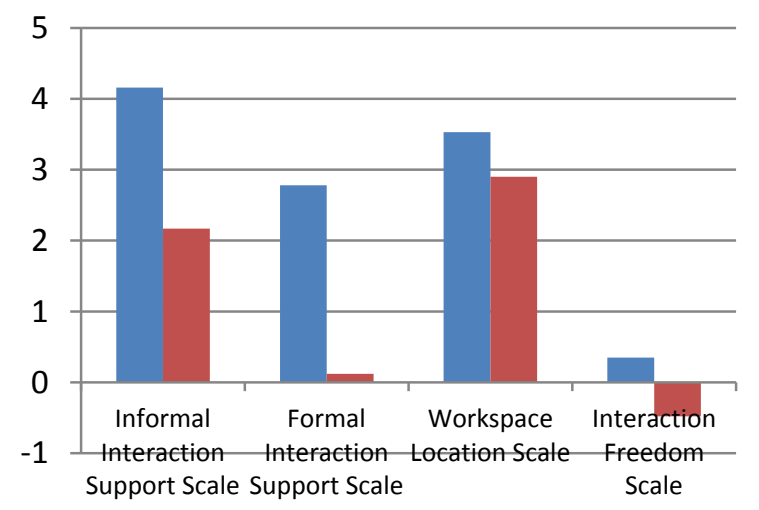

(f) 
Figure 7: Office workers' perception before and after the move given by departments

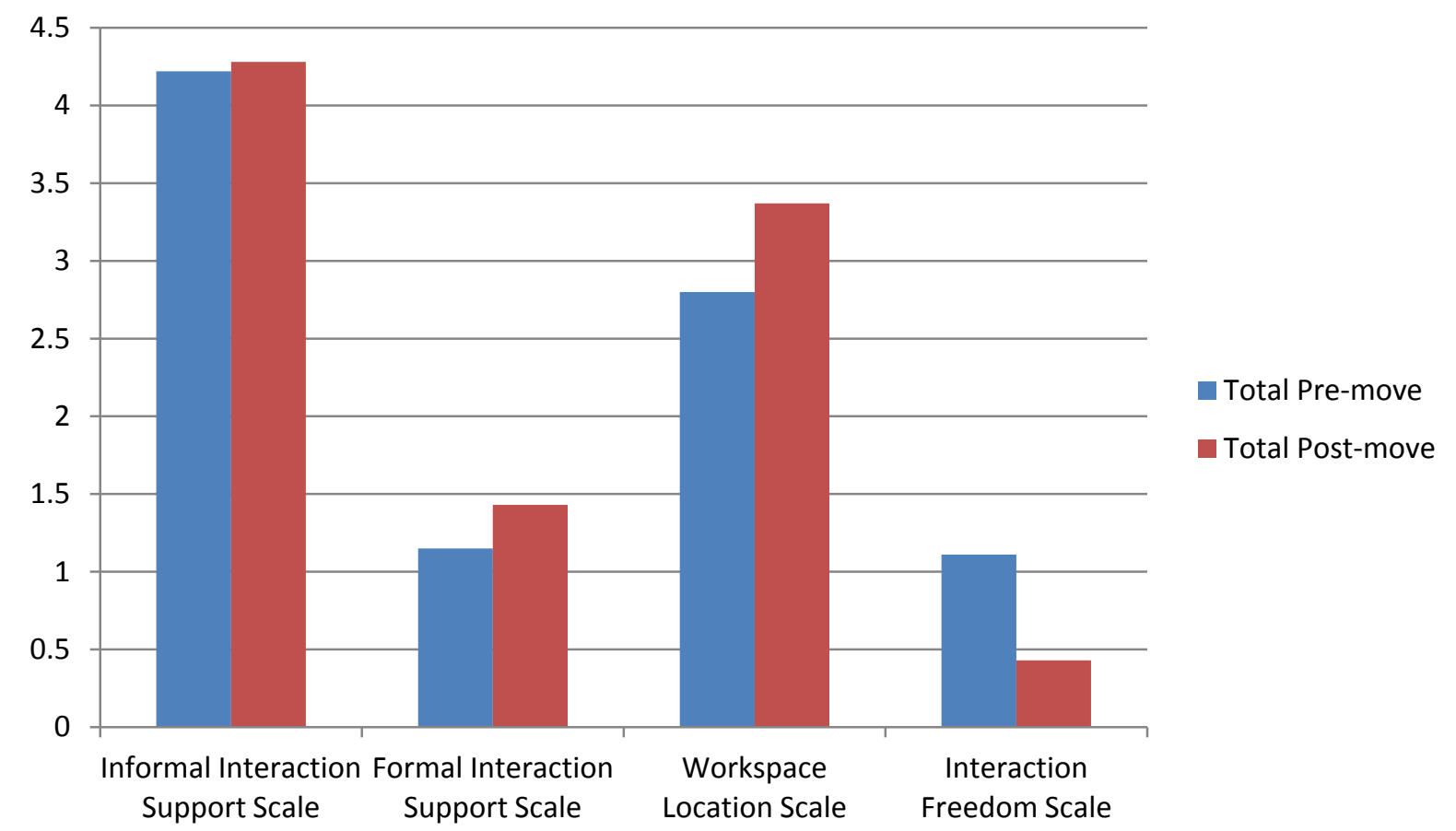

Figure 8: Office workers' perception before and after the move at the organizational level.

Separate bivariate correlational analysis was performed between workplace design factors measured using the informal interaction support, formal interaction support and workplace location scales, and organizational factors measured using the interaction freedom scale for the pre-move and post-move data to find out if the underlying relationships between workplace design and organizational behavior factors considered in this study remained unchanged after colocation (Table 5). The analysis of the pre-move data showed significant correlations between any two scales in all cases but one. The analysis of the postmove data showed significant correlations between any two scales in all cases. In all cases, the correlations were positive suggesting that an improvement in any one of these scales should also mark an improvement in any one of the remaining scales.

Following this, separate regression models were developed for the pre-move and post-move data using informal interaction support, formal interaction support, and workplace location scales as the predictor variables and the interaction freedom scale as the dependent variable (Table 6). The regression models showed the formal interaction support, the informal interaction support, and the workplace location scales as strong predictors of the interaction freedom scale in the organization both before and after the move. Additionally, all three of the predictor variables had significant t-statistics before the move, and two of the 
three had significant $\mathrm{t}$ statistics after the move. The regression analysis thus provided additional support for the view that the underlying relationships between workplace design factors and organizational outcomes considered in this study remained unchanged after colocation.

\begin{tabular}{|c|c|c|c|c|c|}
\hline & & $\begin{array}{l}\text { Informal } \\
\text { Interaction Support } \\
\text { Scale }\end{array}$ & $\begin{array}{l}\text { Formal } \\
\text { Interaction } \\
\text { Support Scale } \\
\end{array}$ & $\begin{array}{l}\text { Workspace } \\
\text { Location Scale }\end{array}$ & $\begin{array}{l}\text { Interaction } \\
\text { Freedom Scale }\end{array}$ \\
\hline \multirow{4}{*}{$\begin{array}{l}\text { Pre- } \\
\text { move }\end{array}$} & Informal Interaction Support Scale & 1 & & & \\
\hline & Formal Interaction Support Scale & $.476 * *$ & 1 & & \\
\hline & Workspace Location Scale & $.594 * *$ & $.497 * *$ & 1 & \\
\hline & Interaction Freedom Scale & $.612 * *$ & 0.017 & $.169 *$ & 1 \\
\hline \multirow{4}{*}{$\begin{array}{l}\text { Post- } \\
\text { Move }\end{array}$} & Informal Interaction Support Scale & 1 & & & \\
\hline & Formal Interaction Support Scale & $.651 * *$ & 1 & & \\
\hline & Workspace Location Scale & $.644 * *$ & $.545^{* *}$ & 1 & \\
\hline & Interaction Freedom Scale & $.712 * *$ & $.361 * *$ & $.208 * *$ & 1 \\
\hline
\end{tabular}

**. Correlation is significant at the 0.01 level (2-tailed).

*. Correlation is significant at the 0.05 level (2-tailed).

Table 5: Bivariate correlation between environmental design and organizational environment factors before and after the move.

\begin{tabular}{|c|c|c|c|}
\hline \multicolumn{4}{|c|}{ Model Summary } \\
\hline & $\mathrm{R}$ & R Square & Adjusted R Square \\
\hline Pre-move & 0.709 & 0.502 & 0.493 \\
\hline Post-move & 0.786 & 0.618 & 0.611 \\
\hline
\end{tabular}

\section{Coefficients}

\begin{tabular}{|l|l|l|}
\hline Variables & $\mathrm{t}$ & sig. \\
\hline Pre-move & & \\
\hline (Constant) & 1.5 & 0.135 \\
\hline $\begin{array}{l}\text { Informal Interaction Support } \\
\text { Scale }\end{array}$ & 12.265 & 0.000 \\
\hline Formal Interaction Support Scale & -4.619 & 0.000 \\
\hline Workspace Location Scale & -2.84 & 0.005 \\
\hline Post-move & & 0.488 \\
\hline $\begin{array}{l}\text { (Constant) } \\
\text { Informal Interaction Support } \\
\text { Scale }\end{array}$ & 14.371 & 0.000 \\
\hline
\end{tabular}




\begin{tabular}{|l|l|l|}
\hline Formal Interaction Support Scale & -1.346 & 0.18 \\
\hline Workspace Location Scale & -6.273 & 0.000 \\
\hline
\end{tabular}

Table 6: Regression models with environmental design factors as the predictor variables and organizational environment as the dependent variable.

\section{Regression Models}

Predictor variables: Informal Interaction Support Scale, Formal Interaction Support Scale, Workspace Location

Dependent variable: Interaction Freedom Scale

\section{DISCUSSION}

Using the data collected from office workers in several departments of an organization located in geographically dispersed buildings and from the same group of workers after they were colocated in one office building, this study looked at the effects of colocation on office workers' perception of workplace design factors measured using the informal interaction support, formal interaction support and the workplace location scales, and their perception of organizational environment factors measured using the interaction freedom scale. These interaction-related factors were included in the study because many studies indicated positive effects of colocation on face-to-face interaction, collaboration, and team effectiveness (for example, Boudreau et al., 2012; Maskell, 2001; Salazar \& Holbrook, 2007; van den Bulte \& Moenaert, 1998). The study investigated if any difference in interaction freedom, to the extent it was predicted by workplace design, would diminish after colocation because workers now used the same workplace; if the effects of colocation on the workers of these departments would be different because they were coming from different locations; and if the underlying relationship between these workplace design and organizational factors would remain unchanged before and after the move.

The study found that the differences among the departments regarding interaction freedom before colocation had diminished after colocation. Though this can be interpreted as a positive outcome of colocation with regards to the departments, one must note the fact that after colocation the overall perception of interaction freedom in this organization had diminished. In an ideal case, departmental differences concerning interaction freedom must diminish and the overall sense of interaction freedom must improve simultaneously in order for colocation to have positive effects on interaction in an organization. 
The study also found that the effects of colocation on workers' perception in the participating departments were different. This finding can be explained by the fact that the participating departments were different in their functions; and that they were coming from workplaces that were somewhat different in their interior layouts and were significantly different in their locations. The fact that in some of these departments the effects of colocations were negative may also indicate that for these departments the old locations worked perfectly well in relation to their functions, and that the move to a new office was not something they needed at this time. This finding raises the question, was the colocation just a real estate management and leadership choice and convenience that ignored internal organizational dynamics? After all, why should an organization need colocation for functionally distinct departments located at different places? Indeed, the findings of the study suggest that any colocation that does not take into account the organizational and design factors of individual departments before colocation may fail to achieve the desired outcomes related to informal interaction support, formal interaction support, workplace location, and interaction freedom after colocation.

Finally, the study found consistent positive relationships among informal interaction support, formal interaction support, workplace location, and interaction freedom. It also found that workplace design factors - informal interaction support, formal interaction support and workplace location — are strong predictors of interaction freedom in the organization. These findings suggest that workplace design features related to formal and informal interaction and workplace location are important for workers' perception of interaction freedom in the organization, and this is true whether the units of an organization are colocated or not.

\section{CONCLUSION}

Colocation predisposes organizational units for more face-to-face interaction opportunities by reducing interpersonal distance among workers coming from geographically-dispersed organizational units, but the findings of the study suggest that there is no guarantee that these workers will avail these interaction opportunities or that they will change their perception of interaction freedom. This suggestion, however, does not contradict the suggestions made by many previous studies that found positive effects of colocation on face-to-face interaction. If anything, the findings of the study indicates that neither decreased interpersonal distance among office workers due to colocation, nor design and/or locational features supporting face-to-face interactions would, by default, improve workers' perception of interaction freedom at workplaces. If a previous study had reported an increase in face-to-face 
interactions due to colocation, then it might have occurred in conjunction with other changes in the organization that the study did not report.

According to this study, the processes by which colocation affect interaction at individual and organizational levels are rather complex. These processes may be influenced by the cultural norms and the rules of permissibility and obligation of individual organizational units taking part in colocation. If this is the case, how should organizational leaders and CRE strategists approach colocation as a management strategy? Should they abandon colocation for the processes by which it affects workers' perception remain unclear? What if, there are immediate financial and process gains to be made by bringing geographically dispersed units together at the same place?

The answer given to these questions by the study is quite unambiguous. Organizational leaders and CRE strategists, who are actively considering colocation as a strategy to improve interaction and team effectiveness, should consider the fact workplace design features can affect workers' perception of interaction freedom in the same way whether these departments are colocated or not. Therefore, if the strategic goal is to improve intra-departmental interaction, then before embarking on an expensive colocation process they may wish to consider improving workplace design to support interaction and collaboration within each department. However, when organizational leaders and CRE strategists are forced to consider colocation for immediate financial and process gains or for improving interdepartmental interactions, they must take appropriate measures to change unit cultures to get the benefits of colocation in terms of improved interaction and team effectiveness. These measures may include incentives, educational programs, and policies to encourage workers of the participating departments to come out of their silos to become a part of the larger organization.

This study helps clarify some aspects of the relationship between colocation and workers' perception of workplace design and interaction freedom. The observations made based on the study cannot be generalized for all types of colocations. Some colocations may not require as much resources as some other colocations that involve people and/or units from geographically dispersed locations. In fact, the effects of colocation on workers' perception may not be that big a factor for colocations that involve moving people around in the workplace or that involve bringing people together virtually without any noticeable workplace design changes. In contrast, colocation can be a good strategic choice for small organizations dispersed at multiple geographical locations when face-to-face interaction is deemed vital for performance and productivity, and when the benefits of colocation in terms of performance and productivity would outweigh its losses in terms of organizational resources. 
Therefore, further studies are needed to further our understanding of the effects of colocation on office workers' perception. Studies comparing the effects of colocation on office workers' perception in similar organizations that move to different kinds of workplaces are needed to understand if workplace design would affect the outcomes of colocation differently. Studies comparing the effects of colocation on office workers' perception in organizations composed of smaller and larger units are needed to find out if colocation would change workers' perception more effectively in smaller units than it would in larger units. Studies comparing the effects of colocation on office workers' perception in similar organizations located in urban and suburban areas are needed to find out if the effects of colocation would vary in different locations that offer different opportunities for access and mobility. Studies comparing the effects of colocation on office workers' perception in similar organizations moving into similar workplaces but use different programs to promote colocation are needed to understand if promotional programs would affect the outcomes of colocation differently.

\section{REFERENCES}

Appel-Meulenbroek, R., \& Feijts, B. (2007). CRE effects on organizational performance: measurement tools for management. Journal of Corporate Real Estate, Vol. 9 No. 4, pp. 218 - 238.

Bechtel, R. B., \& Churchman, A. (2002, Eds.), Handbook of environmental psychology, Wiley, New York, NY.

Bell, P. A., Greene, T., Fisher, J., \& Baum, A. S. (2005, Eds.), Environmental Psychology (5 ${ }^{\text {th }}$ Edition), Lawrence Erlbaum Associates, New Jersey, NJ.

Boudreau, K., Ganguli, I., Gaule, P., Guinan, E., \& Lakhani, K. (2012), “Colocation and Scientific Collaboration: Evidence from a Field Experiment," Harvard Business School Working Paper, No. 13023.

Cannella, A. A., Park, J. H., \& Lee, H. U. (2008), “Top management team functional background diversity and firm performance: examining the roles of team member colocation and environmental uncertainty," Academy of Management Journal, Vol. 51 No. 4, pp. 768-784.

Cassiman, B., Di Guardo, M. C., \& Valentini, G. (2003), “Organizing R\&D Projects to Profit from Innovation: Insights from Co-opetition,” Long Range Planning, Vol. 42 No. 2, pp. 216-233. 
Cramton, C. D. (2001), “The mutual knowledge problem and its consequences for dispersed collaboration," Organization Science, Vol.12, pp. 346-371.

de Croon, E., Sluiter, J., Kuijer, P. P., Frings-Dresen, M. (2005), “The effect of office concepts on worker health and performance: a systematic review of the literature," Ergonomics, Vol. 48, pp. 119 -134.

Gifford, R. (2002), Environmental Psychology: Principles and Practice (3rd edition), Optimal Books, Colville, WA.

Haynes, B. (2007), “An evaluation of office productivity measurement,” Journal of Corporate Real Estate, Vol. 9 No. 3, pp. 144-55.

Hinds, P. J., \& Bailey, D. E. (2003), “Out of sight, out of sync: Understanding conflict in distributed teams," Organization Science, Vol. 14, pp.615-632.

Jones, B. (2009), “The Burden of Knowledge and the 'Death of the Renaissance Man': Is Innovation Getting Harder?" Review of Economic Studies, Vol. 76, pp. 283-317.

Kahn, B. K., \& McDonough, E. F. (1997), “An empirical study of the relationships among co-location, integration, performance, and satisfaction," Journal of Product Innovation Management, Vol. 14 No. 3, pp. $161-178$

Lee, S. Y., Brand, J. M. (2005), "Effects of control over office workspace on perceptions of the work environment and work outcomes," Journal of Environmental Psychology, Vol. 25, No. 3, pp. 323-33.

Maskell, P. (2001), “Towards a knowledge-based theory of the geographic cluster," Industrial and Corporate Change, Vol. 10 No. 4, pp. 921-943.

Martins, L. L., Gilson, L. L., \& Maynard, M. T. (2004), "Virtual teams: What do we know and where do we go from here?" Journal of Management, Vol. 30, pp. 805-835.

McDonough, E. F., Kahn, K. B., \& Barczak, G. (2001), “An investigation of the use of global, virtual, and colocated new product development teams," Journal of Product Innovation Management, Vol. 18, No. 2, pp. 110-120.

Niemi, J., Lindholm, A. (2010),"Methods for evaluating office occupiers' needs and preferences", Journal of Corporate Real Estate, Vol. 12 No. 1, pp. 33 - 46.

Nunnally, J. C. (1978), Psychometric theory (2nd ed.), McGraw-Hill, New York, NY. 
OGP - Office of Governmentwide Policy. (2002), The integrated workplace: a comprehensive approach to developing workspace, Office of Real Property, US General Services Administration, Washington, DC.

Polzer, J. T., Crisp, C. B., Jarvenpaa, S. L., \& Kim, J. W. (2006), "Extending the faultline model to geographically dispersed teams: How colocated subgroups can impair group functioning," Academy of Management Journal, Vol. 49, pp. 679-692.

Rashid, M., Kampschroer, K., Wineman, J., Zimring, C. (2006), "Spatial layout and face-to-face interaction in offices - A study of the mechanisms of spatial effects on face-to-face interaction," Environment and Planning B: Planning and Design, Vol. 33, pp. 825-844.

Rashid, M., Wineman, J., Zimring, C. (2009), "Space, Behavior, and Environmental Perception in Open Plan Offices: A Prospective Study," Environment and Planning B: Planning and Design, Vol. 36, pp. 432-449.

Smith, P. G., \& Reinertsen, D. G. (1998), Developing products in half the time: new rules, new tools. 2nd ed. John Wiley \& Sons, New York.

Salazar, M., \& Holbrook, A. (2007), "Canadian Science, Technology and Innovation Policy: the Product of Regional Networking," Regional Studies, Vol. 4 No. 8, pp. 1129-1141.

Steg, L., van den Berg, A. E., \& de Groot, J. T. M. (2012), Environmental Psychology: An Introduction, John Wiley \& Sons, Oxford, UK.

van den Bulte, C., \& Moenaert, R. K. (1998), "The effects of R\&D team co-location on communication patterns among R\&D, marketing, and manufacturing," Management Science, Vol. 44 No. 11 Part 2, pp. S1-S18.

Wuchty, S., Jones, B., \& Uzzi, B. (2007), “The Increasing Dominance of Teams in Production of Knowledge," Science, Vol. 316 No. 5827, pp.1036-9. 